\title{
Postural Changes in Blood Distribution and Its Relation to the Change in Cardiac Output
}

\author{
Hideo Ueda, M.D., Tadashi Koide, M.D., Iwao Ito, M.D., \\ Hideo Yamada, M.D., Kazutetsu Matsuyama, M.D., \\ and Masahiko Irzuka M.D.
}

\begin{abstract}
Change in cardiac output and blood shift induced by standing were evaluated successively in 18 subjects using external radioisotope counting techniques. Presence of a linear correlation was demonstrated between these 2 hemodynamic variables. When a marked decrease in cardiac output was revealed, blood shift was relatively slight in any subject, and vice versa. This finding was considered to suggest followings. (1) Response of the heart itself might be influenced by posture, and (2) capacity of veins and/or capillaries should be adjusted to compensate for cardiac output changes.
\end{abstract}

$I^{\mathrm{T}}$ $\mathrm{T}$ is well known that the cardiac output in erect position is appreciably lower than that in recumbency in human subjects. ${ }^{1)-6}$ Following explanation of this fact has been widely accepted. Blood in the upper half of the body moves to the lower half in erect position, then ventricular filling pressure decreases. This in turn impairs venous return to the heart, and as the consequence diminishes cardiac output. ${ }^{7}$ However, it is also known that the tone of peripheral vessels is adjusted to compensate for variations of blood distribution and for decrease in cardiac output. These knowledges indicate that the decrease in cardiac output may not necessarily parallel to the degree of blood shift, although it has not been confirmed. The purpose of this investigation is to elucidate the relationship between changes in cardiac output and in blood distribution induced by standing in human subjects.

\section{Materials And Methods}

Eighteen subjects of both sexes from 18 to 63 years of age were examined. These subjects included 8 patients with neurocirculatory asthenia, 6 with hyperthyroidism, 1 with renal hypertension (chronic nephritis), 1 with idiopathic nodal rhythm, and 2 control cases. The diagnosis of neurocirculatory asthenia was made for cases who complained of dyspnea, precordial pain, palpitation, fatigability, dizziness or other symptoms relating to the cardiovascular system, but without any objective sign of cardiovascular involvement on physical and routine laboratory examinations Tokyo.

From the Second Department of Internal Medicine, Faculty of Medicine, University of Tokyo, 
including blood pressure measurement, ECG and X-ray examination of the chest.5), 6) Cases of hyperthyroidism had basal metabolic rate of +26 to +61 per cent. None of these 18 patients had heart failure, edema or arrhythmia.

Cardiac output was measured with external radioisotope dilution method, of which details were previously reported from our laboratory. ${ }^{8}$ ) Thirty-five to $50 \mu \mathrm{c}$. of radioiodinated human serum albumin (RISA) was injected rapidly into the right antecubital vein. Dilution curve was recorded with a detector placed over the cardiac apex and was calibrated against radioactivity of venous blood when $5 \mathrm{~min}$. elapsed after RISA injection. The radioactivity of this blood sample was also used to calculate circulating blood volume. Total volume of injected RISA solutions did not exceed $2 \mathrm{ml}$. and that of collected blood samples was less than $10 \mathrm{ml}$. for each subject.

Blood distribution within the body was evaluated also by the surface counting technique. When the cardiac output determination was finished, a scintillation probe was placed successively over various parts of the body, and radioactivity was measured for $1 \mathrm{~min}$. at each place. These values were regarded as the indices of blood content of the detected parts. These places included (1) tuber parietale of the head, (2) left palm, (3) 3rd intercostal space on the left sternal border, (4) 2nd intercostal space on the right midclavicular line, (5) midpoint between the lung-

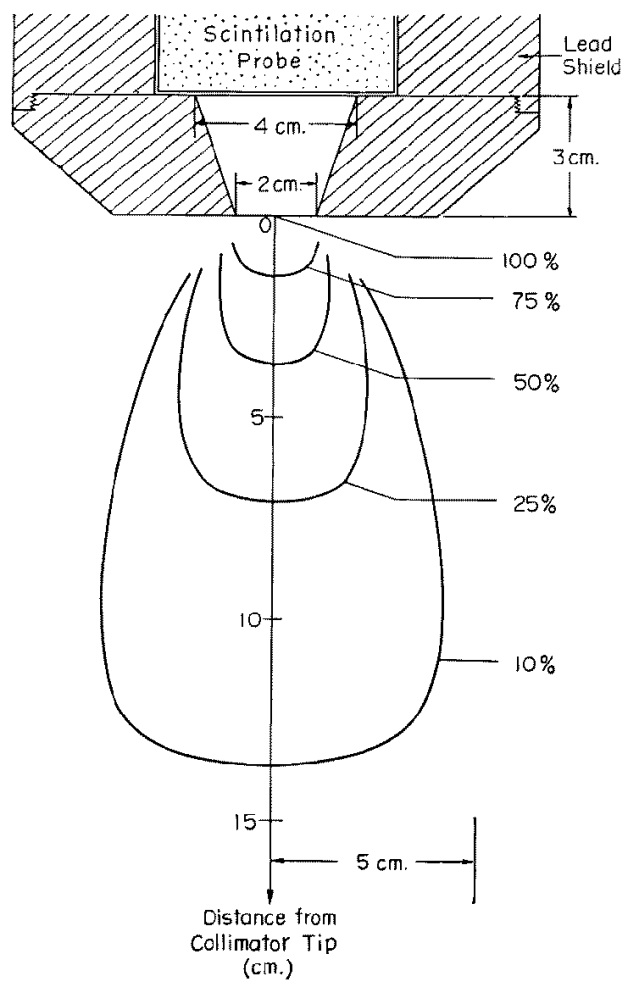

Fig. 1. Characteristics of the collimator.

Isosensitivity lines of 75,50,25 and 10 per cent were shown. Sensitivity was taken for 100 per cent when a point source of $I^{181}$ was placed on the centerline, close to the tip of the collimator. 
liver border and the costal arc on the right midclavicular line, (6) nable, and (7) 10 $\mathrm{cm}$. above the upper tip of the patella in the front of the thigh. They were named briefly (1) "head", (2) "palm", (3) "heart", (4) "lung", (5) "liver", (6) " abdomen", and (7) "thigh" respectively. A lead collimator was mounted to the probe for the measurement of the blood content indices, of which the characteristics were demonstrated in Fig. 1. The detector was placed vertically and in close contact to the skin in most places, but at the "lung " vertically to the frontal plane and at the "liver" laterally with 20 degree tilting in order to minimize the influence of the heart to these places. Reproducibility of this method was estimated in 4 cases. As shown in Fig. 2, the variability was less than \pm 10 per cent within 20 min. interval in most of the cases.

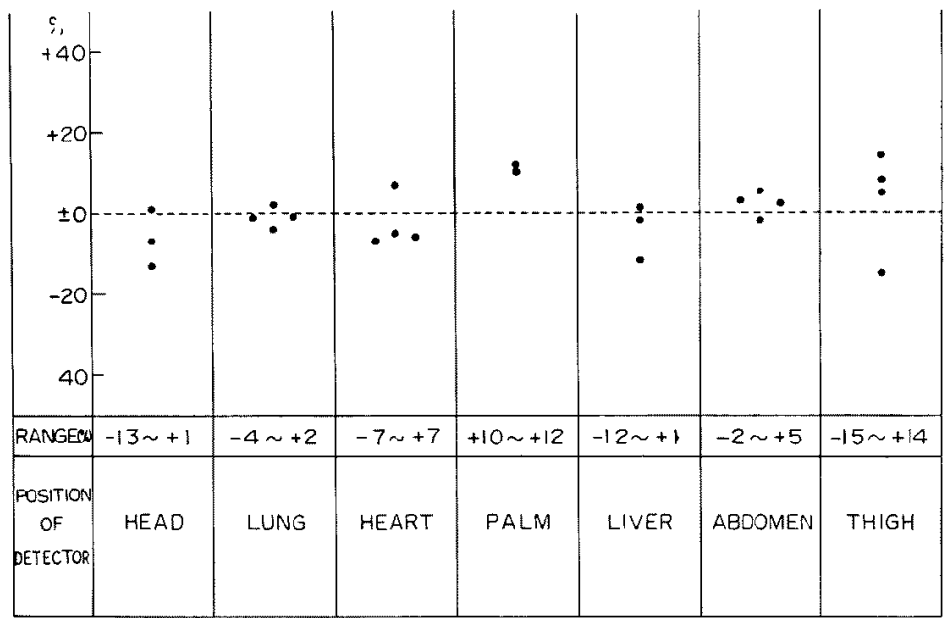

Fig. 2. Reproducibility of the blood content indices.

Blood content indices were measured twice in recumbent position with 20 min. interval in 4 subjects. The difference between the duplicate determinations was within 10 per cent of the first value in most of the cases.

Pulse rate and blood pressure were measured frequently during the whole examination. The latter was measured by auscultation in the left arm using a $12 \mathrm{~cm}$. cuff. Measurement of blood pressure just before that of the " palm " blood content index was avoided since reactive hyperemia might disturb the latter procedure.

Ordinary sequence of these measurements was as follows. The purpose and procedures were explained to each subject at the beginning of the examination. Cardiac output in supine position was first measured, then cardiac output and the blood content indices in standing position were determined successively on the tilt table with 80 degree inclination against the floor. Arms were supported horizontally and laterally by arm rests while the subjects were standing. Then the blood content measurements in supine position were carried out as soon as the blood pressure and pulse rate were stabilized and returned to the level at the beginning of the examination. In order to stabilize the hemodynamic state, at least $10 \mathrm{~min}$. were allowed to elapse prior to the measurements after each alteration of posture. Measurements of cardiac output and of the blood content indices were not simultaneous. The for- 
mer required $5 \mathrm{~min}$. and one series of the latter 10 to $15 \mathrm{~min}$. However, not only pulse rate and blood pressure but the blood content indices themselves were usually stable between 5 and $20 \mathrm{~min}$. after standing. In addition, circulating blood volume did not change by standing (Table II). These findings give evidences of the stability of hemodynamic state during the "standing" examinations. Vasovagal syncope occurred in 5 cases ( 3 of hyperthyroidism and 2 of neurocirculatory asthenia) prior to, or immediately after completion of the measurements in standing position. Data obtained after syncope in these cases are not included in this report.

\section{Results}

In interpretation of changes in the blood content indices, the " recumbent" values were considered to represent 100 per cent and the differences between the "standing" measurements were expressed as percentage increase or decrease deviation from the control values (Table I and Fig. 3). Signifi-

Table I. Changes in the Blood Content Indices Induced by Standing

\begin{tabular}{c|c|c|c|c|c|c|c}
\hline & Head & Lung & Heart & Palm & Liver & Abdomen & Thigh \\
\hline $\begin{array}{c}\text { No. of } \\
\text { Cases }\end{array}$ & 18 & 14 & 18 & 13 & 18 & 17 & 18 \\
\hline Mean (\%) & -3 & -25 & -26 & -16 & -7 & +6 & +56 \\
\hline S.D. (\%) & \pm 16 & \pm 25 & \pm 18 & \pm 28 & \pm 28 & \pm 15 & \pm 25 \\
\hline Range (\%) & $-37 \sim+37$ & $-71 \sim+26$ & $-68 \sim+10$ & $-59 \sim+40$ & $-68 \sim+41$ & $-16 \sim+42$ & $+9 \sim+117$ \\
\hline $\begin{array}{c}\text { Supplement } \\
\text { Significant } \\
\text { Decrease }\end{array}$ & $\begin{array}{l}\text { Significant } \\
\text { Decrease }\end{array}$ & $\begin{array}{l}\text { Significant } \\
\text { Increase }\end{array}$
\end{tabular}

cant changes were observed in the "lung," "heart," and "thigh" $(\mathrm{P}<0.01)$. Average changes were $-25 \pm 25$ (s.D.) \% in the "lung," $-26 \pm 18$ (s.D.) $\%$ in the "heart" and $+56 \pm 25$ (S.D.) \% in the "thigh." Average changes in the other places were insignificant $(\mathrm{P}>0.05)$. No characteristic pattern was revealed for any disease group, nor for cases who fainted after these mesaurements.

Cardiac output and stroke volume decreased by standing in most cases, except in a case of idiopathic nodal rhythm in whom cardiac output of 2.6 L. $/$ min. $/ \mathrm{M}^{2}{ }^{2}$ in supine position increased to $3.5 \mathrm{~L} . / \mathrm{min} . / \mathrm{M} .{ }^{2}$ in erect position (Fig. 4). In neurocirculatory asthenia and in hyperthyroidism, data were combined with those in previous studies $^{(4)-6)}$ and were treated statistically (Table 2 and Fig. 4). These 34 subjects included 18 cases with neurocirculatory asthenia, 12 with hyperthyroidism and 7 control cases. As was cited previous$1 y^{4)-6)}$ cardiac output and stroke volume decreased markedly in many cascs of neurocirculatory asthenia and in those of hyperthyroidism by standing. Average change in cardiac output was $-35 \pm 15$ (s.D.) $\%$ in the former and 


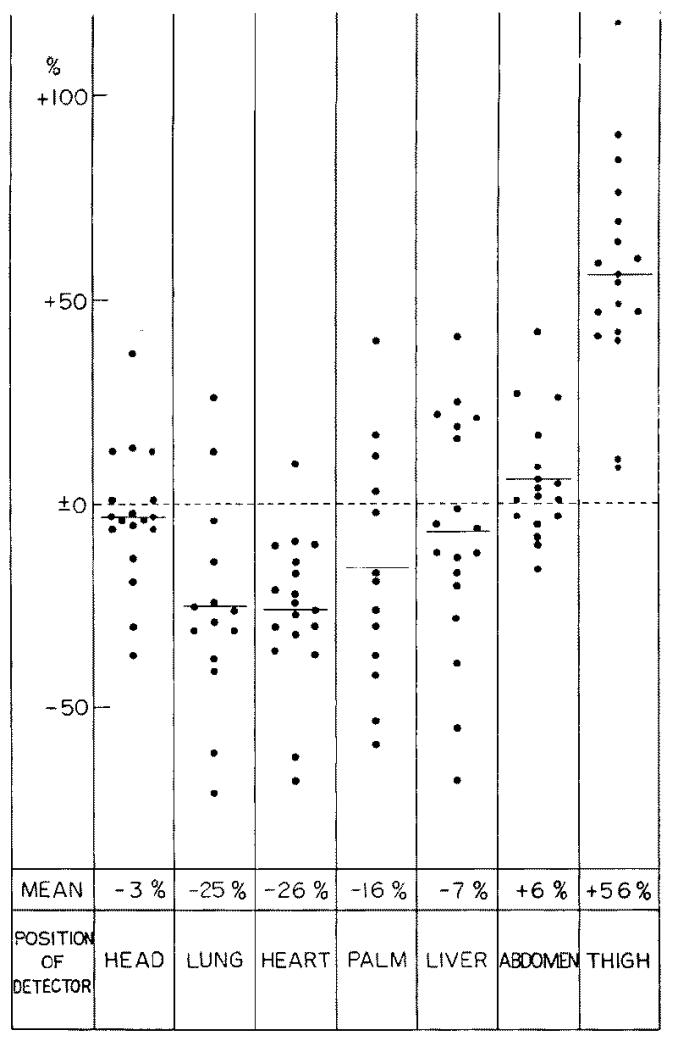

Fig. 3. Changes in the blood content indices induced by standing.

The blood content indices in several parts of the body were measured both in recumbency and 10 to $20 \mathrm{~min}$. after standing in each subject. The difference between both determinations was presented as per cent of the value in supine position. The decrease in the average value in the "lung" and "heart" and the increase in the "thigh" were statistically significant $(\mathbf{P}<0.01)$.

$-35 \pm 20$ (s.D.) $\%$ in the latter in contrast to the value of $-13 \pm 28$ (s.D.) $\%$ in the control group. The difference from the control value was significant in the former $(\mathrm{P}<0.05)$, though not in the latter $(\mathrm{P} \fallingdotseq 0.1)$. Average change in stroke volume in neurocirculatory asthenia, in hyperthyroidism and in control cases was $-44 \pm 15$ (s.D.), $-29 \pm 54$ (s.D.) and $-16 \pm 35$ (s.D.) \% respectively. Circulating blood volume in neurocirculatory asthenia and in hyperthyroidism was $4.4 \pm 0.9$ (s.D.) and $4.7 \pm 1.3$ (s.D.) L., respectively, and was larger than that in the control group ( $3.6 \pm 0.4$ (s.D.) L.), although the differences among the groups were insignificant. Little change was observed in circulating blood volume by standing.

Per cent change in stroke volume was compared to the change in the blood content index in the "thigh" and to that in the "lung" (Fig. 5). There was positive linear correlation to the former $(\mathrm{r}=+0.83, \mathrm{P}<0.01)$ and 
Table II. Hemodynamic Changes Induced by Standing

\begin{tabular}{|c|c|c|c|c|c|c|c|}
\hline & & $\begin{array}{c}\text { Pulse } \\
\text { Rate } \\
\text { (beats/min.) }\end{array}$ & \begin{tabular}{|l} 
Systolic \\
Pressure \\
$(\mathrm{mm} . \mathrm{Hg})$
\end{tabular} & $\begin{array}{c}\text { Diastolic } \\
\text { Pressure } \\
(\mathrm{mm} . \mathrm{Hg})\end{array}$ & $\begin{array}{c}\text { Cardiac } \\
\text { Output } \\
\text { (L./min./ } \\
\left.\text { M. }^{2}\right)\end{array}$ & $\mid \begin{array}{c}\text { Stroke } \\
\text { Volume } \\
\left(\mathrm{ml} / \mathbf{M}^{2}\right)\end{array}$ & $\begin{array}{l}\text { Circulating } \\
\text { Blood } \\
\text { Volume } \\
\text { (L.) }\end{array}$ \\
\hline \multirow{2}{*}{ Control } & Recumbency & $\begin{array}{c}80 \pm 8 \\
(7)^{*}\end{array}$ & $\frac{127 \pm 13}{(7)}$ & $71 \frac{ \pm}{(7)}$ & $4.4 \pm 0.7$ & $\frac{56 \pm 10}{(6)}$ & $3.6 \pm \frac{ \pm}{(5)} 0.4$ \\
\hline & Change & $\begin{array}{c} \pm 13 \pm 7 \\
(7)\end{array}$ & $-\underset{(7)}{-18 \pm 13}$ & $-\frac{1+13}{(7)}$ & $\begin{array}{c}-13 \pm 28 \% \\
(6)\end{array}$ & $\begin{array}{c}-25 \pm 30 \% \\
(6)\end{array}$ & $+2 \frac{2 \pm}{(5)}$ \\
\hline \multirow{2}{*}{$\begin{array}{l}\text { Neuro- } \\
\text { circulatory } \\
\text { Asthenia }\end{array}$} & Recumbency & $\begin{array}{c}78 \pm 9 \\
(18)^{9}\end{array}$ & $\begin{array}{c}117 \pm 9 \\
(18)\end{array}$ & $\begin{array}{c}72 \pm 8 \\
(18) \\
\end{array}$ & $\begin{array}{c}5.7 \pm 1.9 \\
(16)\end{array}$ & $\begin{array}{c}73 \pm 20 \\
(16)\end{array}$ & $\begin{array}{c}4.4 \pm 0.9 \\
\text { (II) }\end{array}$ \\
\hline & Change & $\begin{array}{c} \pm 12 \pm 6 \\
(18)\end{array}$ & $\begin{array}{c}-12 \pm 9 \\
(18)\end{array}$ & $\begin{array}{c}-4 \pm 8 \\
(18)\end{array}$ & $-35 \pm 15 \%$ & $\begin{array}{c}-44 \pm 15 \% \\
(16)\end{array}$ & $\begin{array}{c}+1 \pm 16 \% \\
(11)\end{array}$ \\
\hline \multirow{2}{*}{$\begin{array}{c}\text { Hyper- } \\
\text { thyroidism }\end{array}$} & Recumbency & $\begin{array}{c}94 \pm 19 \\
(12)\end{array}$ & $\begin{array}{c}131 \pm 14 \\
(12)\end{array}$ & $\begin{array}{c}68 \pm 6 \\
(12)\end{array}$ & $\begin{array}{c}9.0 \pm 4.2 \\
(11)\end{array}$ & $\begin{array}{c}103 \pm 39 \\
(9)\end{array}$ & $4.7 \pm 1.3$ \\
\hline & Change & $+\underset{(12)}{11 \pm 16}$ & $-\frac{22 \pm 11}{(12)}$ & $\begin{array}{c}-4 \pm 8 \\
(12)\end{array}$ & $-35 \pm 20 \%$ & $-47 \pm 2+21 \%$ & $\begin{array}{c}-3 \pm 12 \% \\
(11)\end{array}$ \\
\hline
\end{tabular}

Average changes $\pm \mathrm{s}$. D. were displayed for 6 hemodynamic variables and each for 3 different groups including control, neurocirculatory asthenia and hyperthyroidism. Changes in pulse rate and systolic and diastolic blood pressures were presented as absolute values, and those in cardiac output, stroke volume and circulating blood volume as per cent of recumbent values. Thick numerals in the column of the control group indicate that the changes induced by standing are statistically significant $(\mathrm{P}<0.05)$, and those in other groups show that the values are significantly different from those in the control group $(\mathrm{P}<0.05)$.

* The numerals between parentheses indicate the number of cases treated statistically.

negative linear correlation to the latter $(\mathrm{r}=-0.81, \mathrm{P}<0.01)$. Similar relationships were demonstrated between changes in cardiac output and in the blood content indices in the " thigh" $(\mathrm{r}=+0.87, \mathrm{P}<0.01)$ and in the "lung " $(\mathbf{r}=-0.77, \mathrm{P}<0.05)$.

Pulse rate increased, systolic pressure decreased and diastolic pressure did not change by standing. No significant difference was revealed among groups concerning to these parameters.

\section{Discussion and Conclusion}

Validity of methods:

Measurement of radioactivity of the tissues within the detector's view was substituted for direct measurement of blood content in each part of the body. Prerequisits for this substitution for estimation of blood shift are as follows: all of the injected radioactivity must remain within the vascular lumen and geometry of each organs must be unchanged within the detector's view during the whole procedure. The former prerequisit seems to be filled 
since the decrease in blood radioactivity was usually very slow ${ }^{8)}$ and circulating blood volume estimated by RISA dilution did not change by $15 \mathrm{~min}$. standing. As for the latter, it is unlikely that the marked change of radioactivity in the "thigh" or in the "lung" is attributable to geometrical factors, although

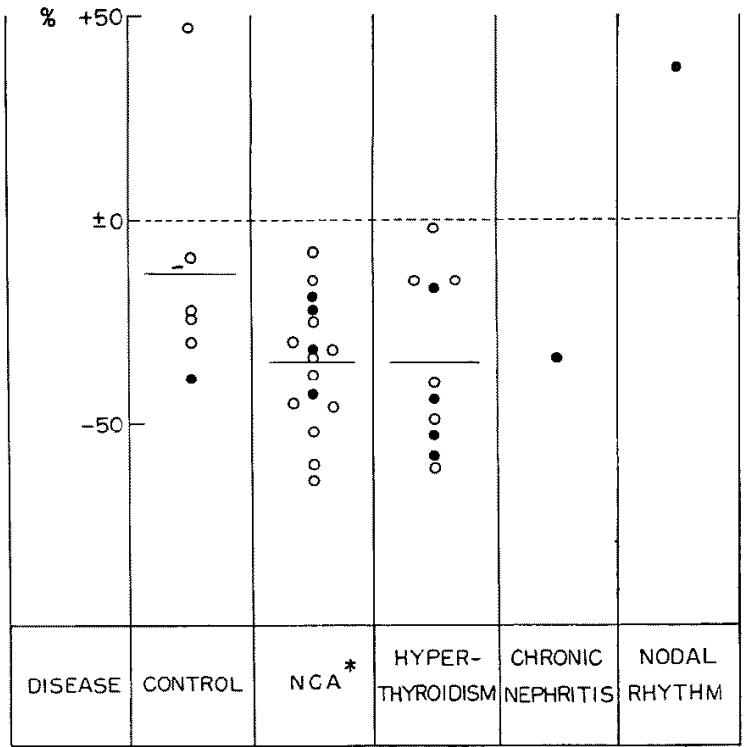

Fig. 4. Changes in cardiac output induced by standing.

Cardiac output changes induced by standing were presented as per cent of the values in recumbency. Cases in which the blood content indices were not measured were also included (open circles). Average change was shown by a horizontal bar for each group. Extreme decrease in cardiac output occurred frequently in neurocirculatory asthenia and in hyperthyroidism. Average decrease in the former was significantly larger than that in the control group $(\mathbf{P}<0.05)$, though not in the latter $(P \fallingdotseq 0.1)$.

* Neurocirculatory asthenia.

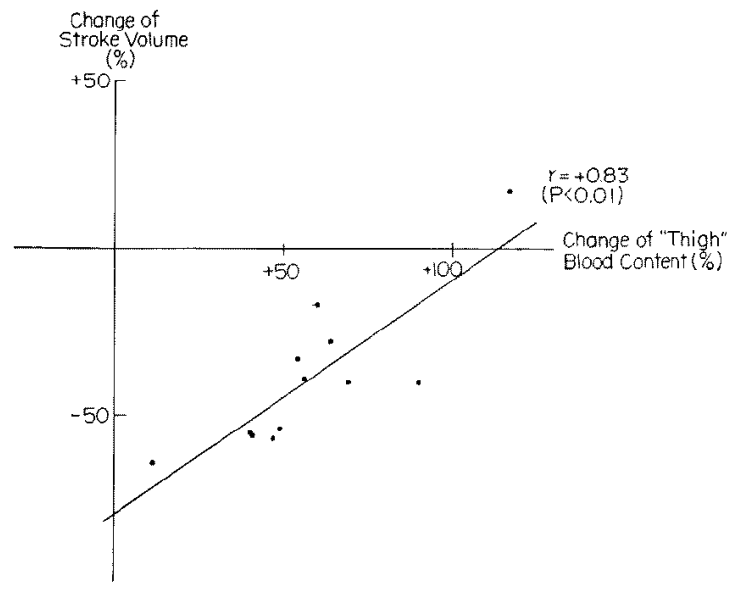



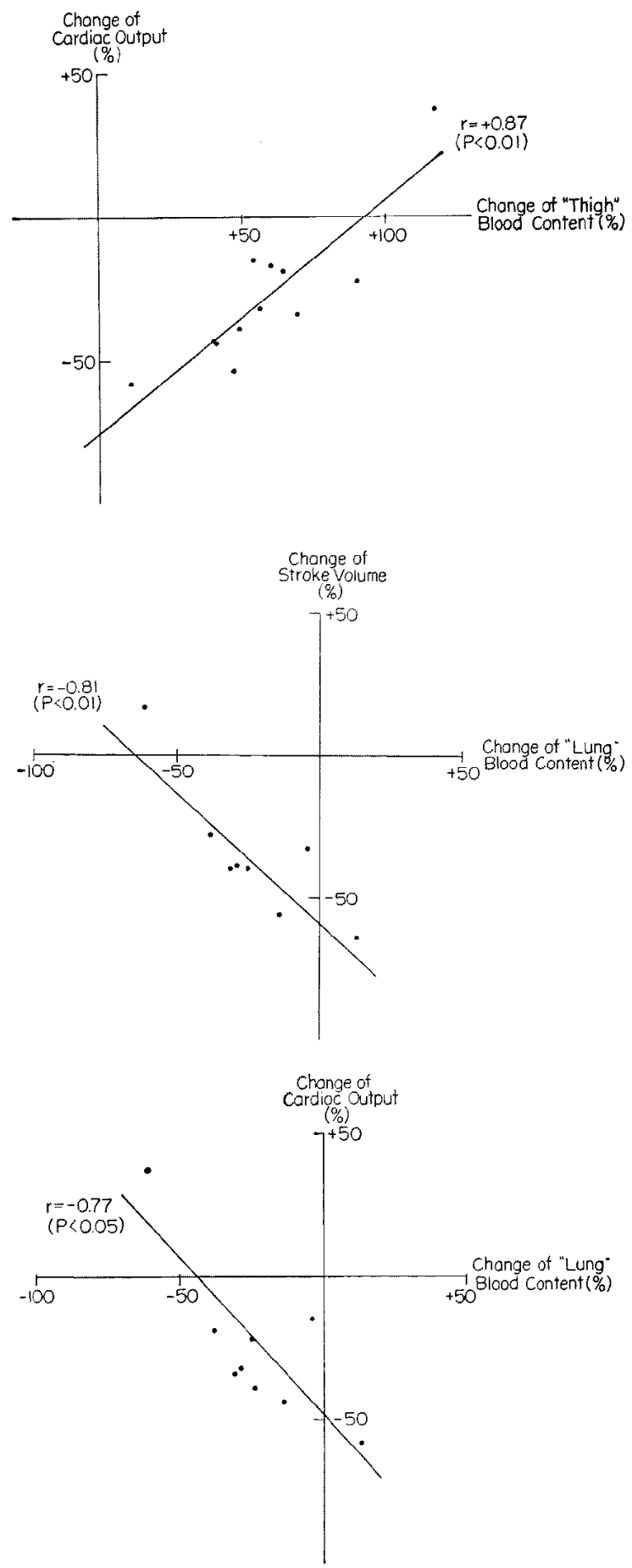

Fig. 5. Correlation between blood shift and cardiac output change induced by standing.

See the text for details. 
shifts of the intestines might be responsible for the changes in the "abdomen". The results obtained by Sjöstrand 9,101 give a support to the authors opinion. He revealed that the predominant changes in blood distribution produced by standing were decrease in blood volume in the heart and lung and its increase in the lower extremities. These findings are consonant to our results. Another report supportive to us was offered by Weissler and his collaborators. ${ }^{11}$ ) They measured the surface counting rate at the right upper quadrant of the chest after intravenous injection of RISA, and confirmed that its relative change produced by tilting was parallel to that of the pulmonary blood volume measured by dye dilution method. Our value of $-25 \%$ for the average change of the "lung" blood content index was closely comparable to that of $-28 \%$ obtained by Weissler et al., although they used a honey-comb collimator to minimize the contribution of radioactivity from the chest muscles to the counting rate and we did not.

Presence of steady state during the whole procedure in standing position should be confirmed since cardiac output and the blood content indices could not be measured simultaneously. Not only pulse rate and blood pressure, but the blood content indices themselves were usually stable from 5 up to 20 min. after standing. In addition, little change was induced by standing in circulating blood volume. The comparison of cardiac output or stroke volume with the blood content indices should therefore be permitted.

Although our method has some shortcomings as discussed above, it is extremely advantageous in another point of view. Mental and physical stresses were minimized by the use of surface counting techniques. This might be emphasized, since even mental stresses are known to yield appreciable changes in hemodynamics. ${ }^{12}$ )

\section{Adjustment of circulation in erect position:}

The mechanism of decrease in cardiac output by standing has been explained as follows. When one stands upright, intravascular pressures are markedly elevated in the lower parts of the body, because large hydrostatic pressures are produced by the long, uninterrupted columns of blood. Blood shifts from the upper to the lower parts of the body, causing distension of the veins in the latter. Corsequently, right ventricular filling pressure diminishes and diastolic distension of the right ventricle is impaired. ${ }^{10), 13), 14 \text { ) }}$ This in turn diminishes stroke volume and subsequently cardiac output ${ }^{1 \text {-7) }}$ by the Starling effect. If the blood shift is prevented by compression of the lower parts of the body, standing causes little change in cardiac output. ${ }^{\text {) }}$ These knowledges suggest that the decrease in cardiac output by standing may be parallel to the blood volume which shifts from the upper to the lower parts of the body. However, several mechnisms are known to work to compensate 
for these events. Systemic blood pressure is maintained by an increase in peripheral vascular resistance despite the decrease in cardiac output. ${ }^{2), 7)}$ Tone of the peripheral veins rises and limit the fall in right ventricular filling pressure, ${ }^{15}$ ) and increased heart rate $^{1)-7)}$ also plays an important role to maintain cardiac output, compensating for the decrease in stroke volume. Since these circulatory adjustments exist together with the effect of gravity, presence of simple parallelism between cardiac output change and blood shift is doubtful in normal men. The results presented here elucidated the presence of the inverse relationship between these 2 parameters. This implies that the mechanisms to hinder the blood shift produced by standing is adjusted against cardiac output so that the more cardiac output decreases the more powerfully they work. This indicates seemingly also that the postural change affects the cardiac activity not only indirectly through the peripheral effect of gravity but also through its more direct influences to the cardiac responsiveness.

Our results demonstrated clearly that the vascular tone of the veins and/or capillaries must play an important role in circulatory adjustment to standing. Average increase of the "thigh" blood content index by standing was over $50 \%$. If it is postulated that this value is directly indicative of true blood content increase, its major parts must be played by the dilatation of the veins and/or capillaries in such a large change in intravascular capacity. Then it seems very natural to speculate that transmural pressures of veins and/or capillaries are adjusted to control the blood shift by standing in order to compensate for cardiac output change. This speculation finds a support in the work of Page and his associates where they revealed vigorous contraction of arm and leg veins and slight increase in central venous pressure immediately after return to horizontal position from tilting. ${ }^{15)}$

Characteristic features of some diseases:

Similarity in hemodynamics in neurocirculatory asthenia and in hyperthyroidism was indicated in prcvious papers from our laboratory. ${ }^{4-6)}$ Recent data were added to them and wcre treated statistically. The results were shown in Table II and in Fig. 4. Thick numerals in the table were those which were significantly different $(\mathrm{P}<0.05)$ from those in control cases. Abnormally high cardiac output and its extreme decrease by standing were frequently observed in both diseases. These provide us with an interest for further investigation, although the difference from control was not always significant for them. Another similarity in both diseases is the frequent occurrence of vasovagal syncope in erect position. Syncope occurred during the ordinary procedures in standing position in 8 of 20 cases with neurocirculatory asthenia and in 6 of 14 cases with hyperthyroidism. In contrast, none of 7 control cases experienced such an attack. These similarities and the 
similarity in subjective symptoms-palpitation, precordial discomfort, shortness of breath and easy fatigability-make us imagine the presence of common disorders, probably of autonomic nerve function, in both disease entities. The study of blood shift produced by standing gave us no clue in this respect.

Standing induced an increase in cardiac output and in stroke volume in a case of idiopathic nodal rhythm. It could not be elucidated whether this is common in this disease or not. Similar response was previously observed in one of control cases (Fig. 4).

\section{Summary}

(1) Gardiac output and the blood content indices of the several parts of the body were measured in 18 subjects including patients with various diseases using external radioisotope counting techniques. Changes in these 2 parameters induced by standing were compared with each other.

(2) Average changes in blood distribution produced by standing were as follows. Decrease in blood content in the "lung" $(-25 \%)$ and in the "heart" $(-26 \%)$ and increase in the "thigh" $(+56 \%)$ were statistically significant. No significant change was revealed in the "head", "palm", "liver" and "abdomen".

(3) Cardiac output and stroke volume decreased by standing in most of the cases. Recent data were added to those reported previously and were treated statistically. Average decrease in cardiac output was $-13 \%$ in 6 control cases, $-35 \%$ in 16 cases with neurocirculatory asthenia and $-35 \%$ in 10 cases with hyperthyroidism. The difference was significant between control and neurocirculatory asthenia. Standing induced a substantial increase in cardiac output in a case of idiopathic nodal rhythm, although there remains a doubt whether it is the ordinary response in this disease.

(4) Significant linear correlation was revealed between per cent change of blood content in the "thigh" or in the "lung" and that of cardiac output or stroke volume induced by standing. Minimal blood shift was observed when the latter was extreme, and vice versa. This implies as follows: reactivity of the heart might be influenced by posture, and transmural pressure of veins and/or capillaries is probably adjusted, as in arterioles, to compensate for changes in cardiac output.

\section{REFERENCES}

1. McMichael, J. and Sharpey-Schafer, E. J.: Brit. Heart J. 6 : 33, 1944.

2. Stead, E. A., Jr., Warren, J. V., Merrill, A. J., and Brannon, E. S. : J. Clin. Invest. 24: $326,1945$. 
3. Reeves, J. T., Grover, R. F., Blount, S. G., Jr., and Filley, G. F.: J. Appl. Physiol. 16: 283, 1961.

4. Ueda, H. et al.: J. Jap. Soc. Int. Med. 50: 937, 1961.

5. Ito, I. et al.: Naika 7: 525, 1961 (in Japanese).

6. Ueda, H. and Ito, I.: Jap. Circulat. J. $27: 22,1963$.

7. Weissler, A. M., Leonard, J. J., and Warren, J. V.: J. Clin. Invest. $36: 1656,1957$.

8. Ueda, H., Iio, M., Koide, T., Nakanishi, A., Ito, I., Kameda, H., and Yasuda, H.: Jap. Heart J. $2: 309,1961$.

9. Sjöstrand, T.: Acta Physiol. Scand. 26 : 312, 1952.

10. Sjöstrand, T.: Physiol. Rev. 33 : 202, 1953.

11. Weissler, A. M., McGraw, B. H., and Warren, J. V.: J. Appl. Physiol. 14 : 531, 1959.

12. Brod, J.: Brit. Hcart J. 25: 227, 1963.

13. Brigden, W., Howarth, S., and Sharpey-Schafer, E. B.: Clin. Sc. 9: 79, 1950.

14. Linderholm, J. and Strandell, T.: Acta Med. Scand. 162: 247, 1958.

15. Page, E. B., Hickam, J. B., Sieker, H. O., McIntosh, H. D., and Pryor, W. W. : Circulation 11 : $262,1955$. 